\title{
Two parallel trench-normal fault planes within the Pacific slab associated with the 1994 and 2000 Kurile earthquakes as revealed by simultaneous relocation of their main shocks and aftershocks
}

\author{
Tomoya Harada ${ }^{1 *}$ and Katsuhiko Ishibashi ${ }^{2}$ \\ ${ }^{1}$ Graduate School of Science and Technology, Kobe University, Kobe 657-8501, Japan \\ ${ }^{2}$ Research Center for Urban Safety and Security, Kobe University, Kobe 657-8501, Japan
}

(Received February 6, 2007; Revised June 21, 2007; Accepted June 29, 2007; Online published July 27, 2007)

\begin{abstract}
The 1994 Hokkaido-Toho-Oki $\left(M_{\mathrm{w}} 8.3\right)$ and the 2000 Nemuro-Hanto-Oki $\left(M_{\mathrm{w}} 6.8\right)$ earthquakes have been regarded as great/large intraslab events within the subducted Pacific plate along the southern Kurile trench. Determining which nodal planes of their mechanism solutions are actual fault planes and whether or not the 2000 event occurred on the southwestern extension of the 1994 fault plane have been problematic. In order to clarify these points, we examine the relative location of their main-shock and aftershock distributions accurately by simultaneous relocation of their hypocenters using the Modified Joint Hypocenter Determination (MJHD) method. The result clearly shows that the two earthquakes occurred on trench-normal shallow-dipping fault planes within the Pacific slab, apart from and parallel to each other. Therefore, the 2000 earthquake was not a rupture on the deeper extension of the 1994 fault plane, but one on another fault plane. A large intraslab earthquake $\left(M_{\mathrm{w}} 7.8\right.$; depth, about $\left.100 \mathrm{~km}\right)$ occurred to the northwest of the 1994 event in 1978, and two trenchnormal fracture zones exist outside the trench to the southeast of the 1994 and 2000 events. Therefore, these three intraslab great/large earthquakes are considered to have been ruptures along pre-existing trench-normal weak zones within the subducted Pacific plate.
\end{abstract}

Key words: 1994 Hokkaido-Toho-Oki earthquake, 2000 Nemuro-Hanto-Oki earthquake, Kurile trench, intraslab earthquake, simultaneous relocation, trench-normal weak zone.

\section{Introduction}

The 1994 Hokkaido-Toho-Oki earthquake occurred off Shikotan Island in the southern Kurile subduction zone on 4 October $1994\left(13: 22: 57.68 \mathrm{GMT}, 147.3804^{\circ} \mathrm{E}, 43.6597^{\circ} \mathrm{N}\right.$, depth $28.0 \mathrm{~km}$ (fixed), $M_{\mathrm{w}} 8.3$ ). About five years after the 1994 event, the 2000 Nemuro-Hanto-Oki earthquake took place southwest of the former event on 28 January 2000 $\left(14: 21: 05.79 \mathrm{GMT}, 146.8350^{\circ} \mathrm{E}, 43.0500^{\circ} \mathrm{N}\right.$, depth 46.0 $\mathrm{km}, M_{\mathrm{w}} 6.8$ ). Here, the hypocenter parameters are after the International Seismological Centre (ISC) (2005) and $M_{\mathrm{w}}$, from the Global Centroid Moment Tensor (CMT) Catalog (http://www.globalcmt.org/CMTsearch.html). Their mainshock epicenters and CMT solutions are shown in Fig. 1. It should be noted that the 1994 and 2000 focal mechanisms are very similar to each other.

The southern Kurile subduction zone, where the Pacific plate is being subducted beneath the Okhotsk plate at the Kurile trench at a rate of about $8 \mathrm{~cm} / \mathrm{yr}$ (Seno et al., 1996), has a history of recurring great interplate earthquakes (Utsu, 1972). The 1994 earthquake was first regarded as a great interplate event since it was located near the last great in-

\footnotetext{
* Now at Research Center for Urban Safety and Security, Kobe University, Kobe 657-8501, Japan.

Copy right (C) The Society of Geomagnetism and Earth, Planetary and Space Sciences (SGEPSS); The Seismological Society of Japan; The Volcanological Society of Japan; The Geodetic Society of Japan; The Japanese Society for Planetary Sciences; TERRAPUB
}

terplate event off Shikotan Island in $1969\left(M_{\mathrm{w}} 8.3\right)$. But, later it turned out to be a great intraslab event within the subducted Pacific plate (e.g. Kikuchi and Kanamori, 1995).

An important problem still controversial for the 1994 earthquake is to determine which nodal plane of the mechanism solution is the fault plane. Kikuchi and Kanamori (1995) suggested that the steep (trench-parallel) plane was the fault plane based on a body-wave analysis and comparison between the coseismic subsidence at Shikotan Island and crustal deformation predicted by their model. On the other hand, Tanioka et al. (1995) proposed that the shallowdipping (trench-normal) plane was the fault plane and that this earthquake was a trench-ward extension of the 1978 rupture which had torn the Pacific slab left-laterally around the depth of $100 \mathrm{~km}$ (Fig. 1). However, they also showed that either nodal plane could explain the observed tsunami waveforms and displacements at GPS stations in Hokkaido. Other studies on geodetic and tsunami data (e.g. Tsuji et al., 1995) could not identify the 1994 fault plane clearly.

Takahashi and Hirata (2003) considered that the 2000 earthquake provided a clue to resolve the 1994 fault-plane debate, relocated its main shock and aftershocks, and concluded that the 2000 event had been an intraslab rupture on a trench-normal shallow-dipping fault plane. They further suggested that the 1994 faulting had also occurred on a trench-normal shallow-dipping fault plane and the 2000 event had been the southwestward continuation of the 1994 faulting based on the relative location of the two events and 


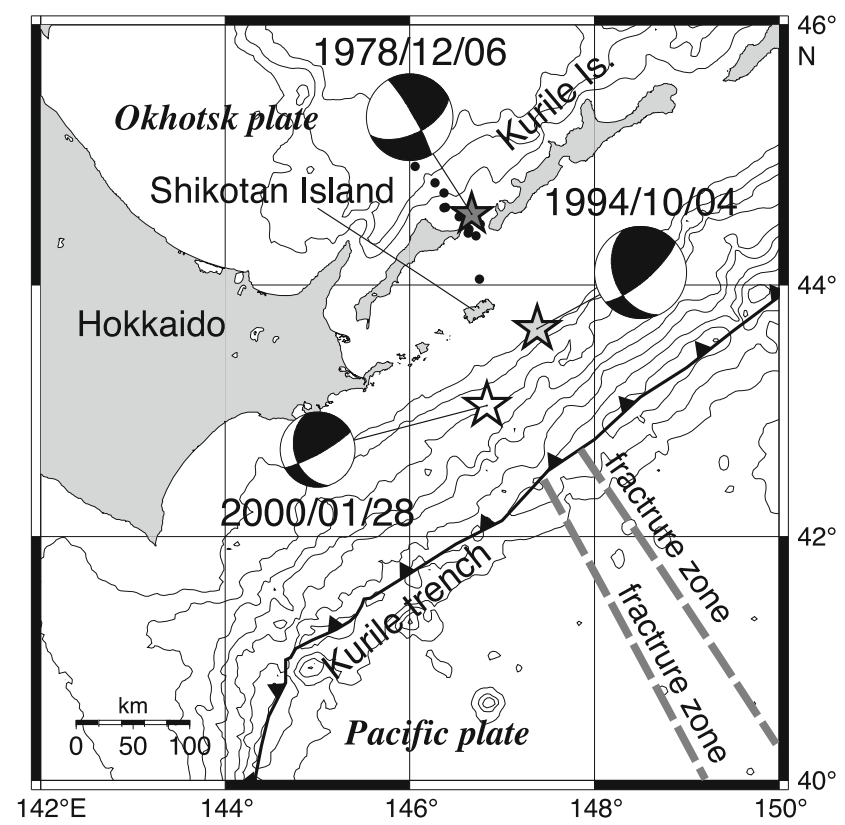

Fig. 1. Submarine topography, tectonic setting and epicenters of three intraslab earthquakes around Shikotan Island in the southern Kurile subduction zone. The thick solid line indicates the trench axis. The dark gray, light gray, and white stars represent the epicenters of the 1978, 1994, and 2000 main shocks, respectively. The dots show epicenters of the 1978 aftershocks. The epicentral locations are after the International Seismological Centre (2005). Moment-tensor solutions for the three earthquakes are from the Global Centroid Moment Tensor (CMT) Catalog (http://www.globalcmt.org/CMTsearch.html). The thick broken lines denote fracture zones in the Pacific plate (Hilde et al., 1976).

the similarity between their focal mechanisms. However, there is a big problem in their interpretation that they did not relocate the 1994 main shock and aftershocks and relied on poor hypocenter constraint of the 1994 sequence. Therefore, Takahashi and Hirata's (2003) interpretation is still open to discussion.

In this paper, we try to identify the fault planes of the 1994 and 2000 earthquakes and to clarify the relationship between these two events by re-examining hypocenter distributions of their main shocks and aftershocks. Katsumata et al. (1995) suggested that the 1994 earthquake had a steep fault plane from its main-shock and aftershock distribution determined by a local seismic network in Hokkaido. However, we think that the relocated hypocenter locations might have been affected by local velocity structure heterogeneity and by the poor network distribution which was located on one side of the aftershock area. In order to overcome this difficulty, we conduct a simultaneous relocation of the 1994 and 2000 main shocks and aftershocks using Hurukawa's (1995) Modified Joint Hypocenter Determination (MJHD) method.

\section{Method and Data}

In the case of the 2004 off the Kii Peninsula earthquakes, recent large offshore events within the subducting oceanic plate (in this case, the Philippine Sea plate), for which Japanese seismic observation networks had insufficient station coverage, Enescu et al. (2005) adopted a Double-Difference method to determine better hypocentral

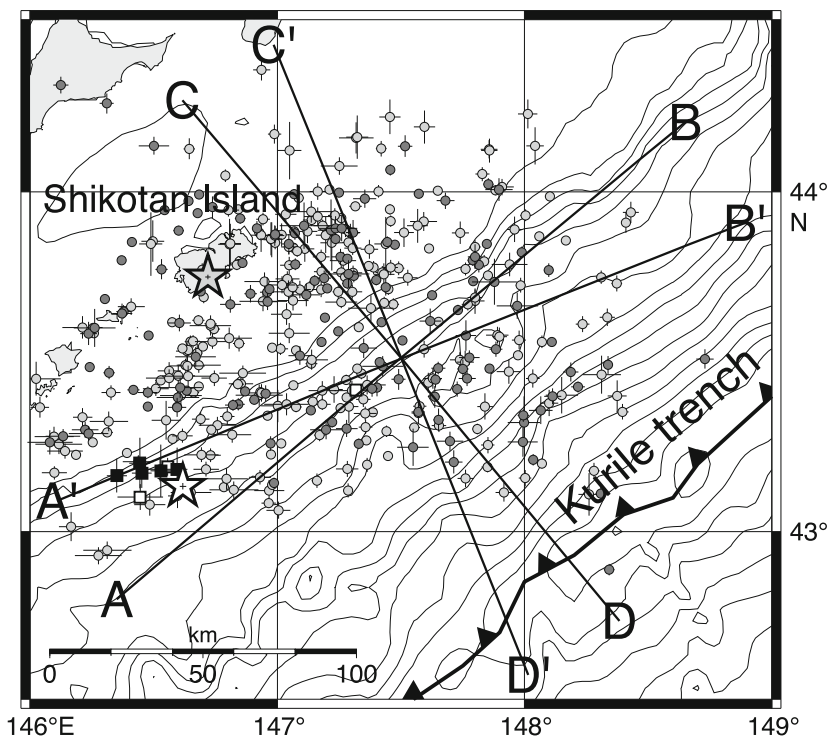

Fig. 2. Distribution of 420 best-relocated epicenters. The light gray star, dark gray circles, and light gray circles represent the main shock, one-day aftershocks, and one-month aftershocks of the 1994 earthquake, respectively. The white star, black squares, and white squares represent the main shock, one-day aftershocks, and one-month aftershocks of the 2000 earthquake, respectively. Error bars show standard errors of latitude and longitude. Lines A-B and C-D are parallel and perpendicular to the steep nodal plane of the 1994 CMT solution, and lines $\mathrm{A}^{\prime}-\mathrm{B}^{\prime}$ and $\mathrm{C}^{\prime}-\mathrm{D}^{\prime}$ are perpendicular and parallel to the shallow-dipping one.

distribution of the aftershocks. In the present study, however, we use the Modified Joint Hypocenter Determination (MJHD) method developed by Hurukawa and Imoto (1992) and Hurukawa (1995) for teleseismic events employing the worldwide ISC data. This method imposes a constraint that station corrections are independent of both distances and azimuths of stations from the center of the source region, in order to make the JHD method stable even if the station coverage is poor. As a result, the MJHD method provides very accurate relative locations (Hurukawa and Imoto, 1992; Hurukawa, 1995).

Hurukawa (1995) relocated the 1994 main shock and its 19 aftershocks, whose data had been reported by the National Earthquake Information Center (NEIC) of the U.S. Geological Survey (USGS), using the MJHD method, and concluded that the fault plane was the trench-parallel steep plane. However, the number of relocated hypocenters was small and the result seems to need further examination.

We simultaneously relocated hypocenters of the 1994 and 2000 main shocks and their aftershocks during the first month after each main shock (hereinafter "one-month aftershocks" for short) listed in the ISC Bulletin (International Seismological Centre, 2005) within the area of $42.5-44.5^{\circ} \mathrm{N}$ and $146.0-149.0^{\circ} \mathrm{E}$, and with focal depths less than $150 \mathrm{~km}$. The numbers of the 1994 and 2000 hypocenters are 3627 and 108 , respectively.

In the relocation, we used about 86,000 $P$-wave arrival times observed at 761 global stations (International Seismological Centre, 2005). The travel-time table ak135 from Kennett et al. (1995) was employed. Earthquakes and stations were selected based on the following two criteria: (1) 

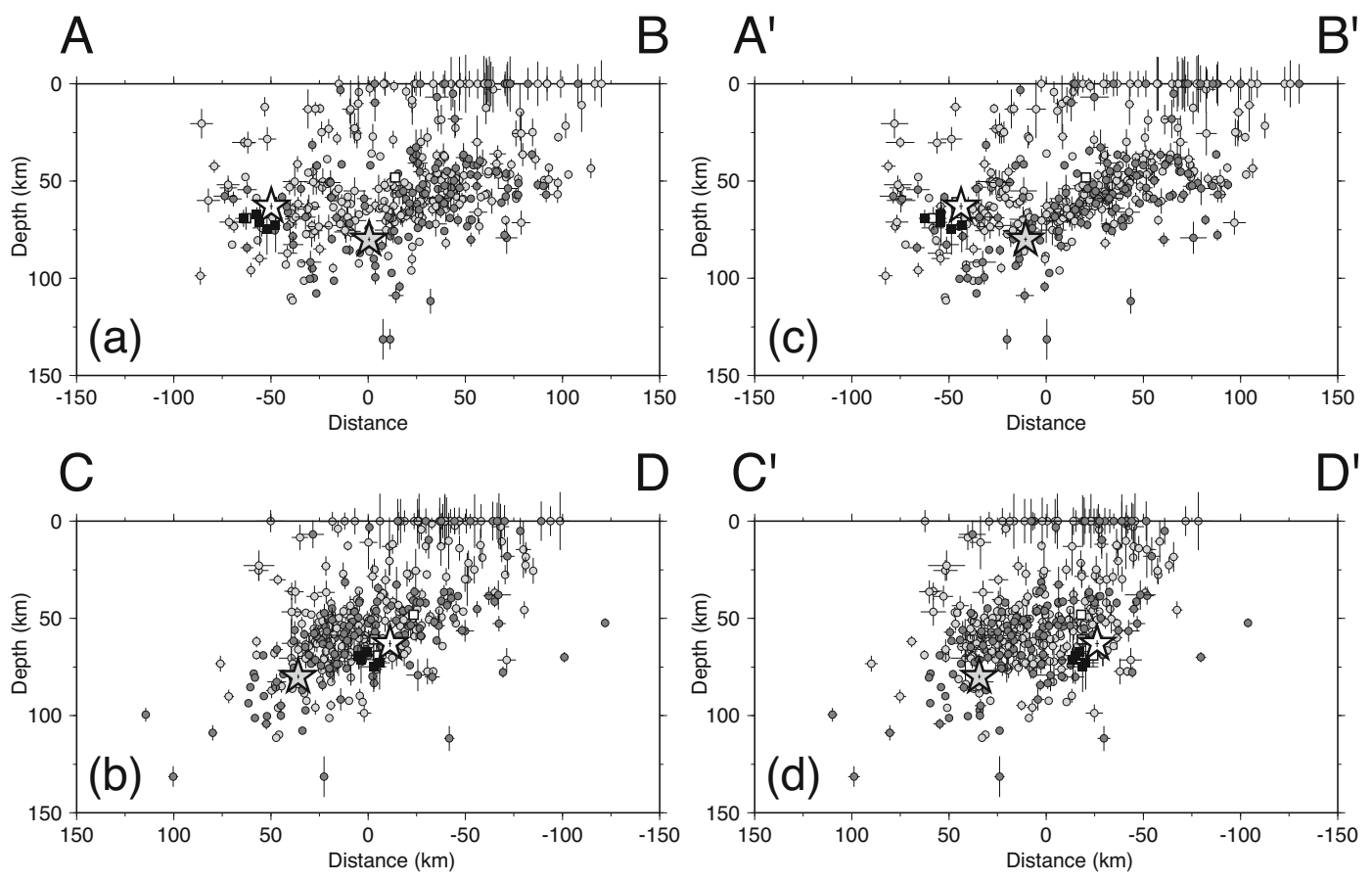

Fig. 3. Vertical cross sections of hypocenter distribution of earthquakes shown in Fig. 2 along the lines A-B (a), C-D (b), $A^{\prime}-B^{\prime}$ (c), and $C^{\prime}-D^{\prime}$ (d). Symbols are the same as in Fig. 2. Horizontal and vertical error-bars are also shown.

The minimum number of stations that observed each event is 10. (2) The minimum number of events observed at each station is 10 . Poor readings for which travel-time residuals were greater than $2.0 \mathrm{~s}$ were excluded. Finally, 1288 and 41 hypocenters of the 1994 and 2000 events, respectively, were accurately relocated.

\section{Results}

Among the 1329 relocated hypocenters we chose 420 with the smallest errors, 411 for 1994 and 9 for 2000, whose standard errors of latitude, longitude, and focal depth are within $0.1^{\circ}, 0.1^{\circ}$, and $15 \mathrm{~km}$, respectively, in order to delineate reliable fault planes of the two main shocks. Here, we follow the straightforward idea that the one-day or so aftershock distribution indicates which nodal plane of the mainshock focal mechanism is an actual fault plane. This idea was first applied by Kanamori (1971) to the 1923 Kanto, Japan, earthquake and has been effectively used in numerous case studies, though, of course, not all aftershocks occur on the main-shock fault plane with the same focal mechanism as the main shock.

Figure 2 shows the distribution of the 420 best-located epicenters. The one-day aftershock area of the 1994 event is almost the same as that of one-month, which indicates that the aftershock area was not expanding horizontally during the month after the main shock. The 1994 aftershocks are widely distributed from Shikotan Island to the vicinity of the trench axis, and the distribution indicating a trenchparallel steep fault plane is not found. The 2000 aftershock area is also broad rather than a lineation parallel to the trench axis.

Figures 3(a)-(d) are vertical cross sections of the bestlocated hypocenters along the lines A-B, C-D, $\mathrm{A}^{\prime}-\mathrm{B}^{\prime}$, and $\mathrm{C}^{\prime}-\mathrm{D}^{\prime}$ in Fig. 2. Lines $\mathrm{A}-\mathrm{B}$ and $\mathrm{C}-\mathrm{D}$ are parallel and per- pendicular, respectively, to the trench-parallel steep nodal plane of the 1994 and 2000 CMT solutions, and lines A'$\mathrm{B}^{\prime}$ and $\mathrm{C}^{\prime}-\mathrm{D}^{\prime}$ are perpendicular and parallel, respectively, to the trench-normal shallow-dipping plane of the two solutions. In these figures, vertical error-bars of the relocated hypocenters are small except for those near the surface. Therefore, the accuracy of the relocated hypocenters is considered good enough for delineating the 1994 and 2000 fault planes. The 1994 one-day aftershock distribution almost coincides with that of the one-month aftershocks, suggesting that the 1994 aftershocks were not expanding vertically during the month after the main shock.

By comparing four vertical cross sections in Fig. 3, it is obvious that the 1994 main shock and aftershocks are concentrated mainly along a trench-normal shallow-dipping plane (Fig. 3(c)), strongly suggesting that this plane is the fault plane of this earthquake. The depth range of the 1994 concentrated aftershocks is roughly from 40 to $80 \mathrm{~km}$, though the absolute depth control is not necessarily very well, and the main shock was relocated at the northwestern bottom of the aftershock area. Thus, the 1994 earthquake is interpreted as an intraslab event having a trench-normal shallow-dipping (about $30^{\circ}$ from northeast to southwest) fault plane of about $100 \mathrm{~km}$ (length) $\times 100 \mathrm{~km}$ (width) in area and with the rupture initiation at the bottom northwestern corner.

The ISC's epicenter of the 1994 main shock is about 60 $\mathrm{km}$ away from the relocated epicenter, and the focal depth is $28.0 \mathrm{~km}$. Although our relocation is not absolute one, our result seems better than the ISC's because the quality of the travel-time data used in the MJHD calculation, which were selected from the ISC data, is much better than that of the ISC location. The ISC's depth is fixed one, and the centroid depth is $68.2 \mathrm{~km}$ according to the Global CMT Catalog. 
The 2000 earthquake seems to have the same fault type as that of 1994, though it is not as clear as 1994 because the number of aftershocks is small. But, at least we can conclude that the fault of the 2000 earthquake is completely different from that of the 1994 earthquake, that is, the 2000 event was not the extended rupture of the 1994 fault plane. The 2000 aftershocks concentrate around a depth of about $70 \mathrm{~km}$, and the main shock was relocated at the upper edge of its aftershock distribution. It should be noted that a considerable number of the 1994 aftershocks took place in and around the 2000 aftershock area, showing a parallel distribution to the 1994 major aftershock area. The distance between these two clusters is about $30 \mathrm{~km}$.

\section{Discussion and Conclusions}

Takahashi and Hirata (2003) suggested that the 2000 earthquake had been a southwestward extension of the 1994 faulting by examining the 1994 and 2000 hypocenters based on the JMA (Japan Meteorological Agency) catalog. However, the 2000 main shock and aftershock distribution revealed in the previous section obviously shows that the 2000 earthquake ruptured a fault plane different from the 1994 fault plane.

On December 6, 1978, a large intermediate-depth earthquake $\left(M_{\mathrm{w}} 7.8\right)$ occurred at a depth of about $100 \mathrm{~km}$ beneath the Kunashiri strait to the northwest of the 1994 source region (Fig. 1). This event has been interpreted as a trenchnormal tearing within the Pacific slab (Kasahara and Sasatani, 1985). Tanioka et al. (1995) paid special attention to the lineation of the 1978 and 1994 aftershock distribution, base on which they considered that the 1994 fault plane was the trench-normal plane and the two events had tore the Pacific slab left-laterally. According to Hilde et al. (1976), two right-lateral trench-normal fracture zones are tearing the $\mathrm{Pa}-$ cific plate at the southeastern trench outer-zone of the 1994 and 2000 aftershock areas (Fig. 1). Thus, it seems probable that the 1994 fault plane links the 1978 fault plane and one of the fracture zones, forming a trench-normal weak zone within the Pacific slab, though the slip motion is opposite of the fracture zone. Also, the 2000 event may have occurred on the extension of the southern fracture zone (Fig. 1). Takahashi and Hirata (2003) pointed out the possibility that $M$ 7-class earthquakes had occurred around the 2000 source region in 1935 and 1964. The same situation that the submarine fracture outside the trench may continue to the subducted oceanic plate, causing large earthquakes, is discussed by Miyoshi and Ishibashi (2005) in the Kii Peninsula region along the Nankai trough, southwest Japan.

In conclusion, we relocated the 1994 main shock, its 3626 one-month aftershocks, the 2000 main shock, and its 107 one-month aftershocks simultaneously by the $\mathrm{Hu}-$ rukawa's (1995) Modified Join Hypocenter Determination (MJHD) method employing the ISC's global $P$-wave data. Based on the distribution of the 420 best-relocated hypocenters, both the 1994 Hokkaido-Toho-Oki $\left(M_{\mathrm{w}}\right.$ 8.3) and the 2000 Nemuro-Hanto-Oki $\left(M_{\mathrm{w}} 6.8\right)$ earthquakes have proved to be intraslab events within the Pacific plate subducted at the southern Kurile trench having trench-normal and westward-shallowly-dipping fault planes. The two fault planes, parallel to each other, are separated by about $30 \mathrm{~km}$. They are considered to be pre-existing intraslab weak zones continuing to the 1978 source region to the northwest and trench outer-zone fracture zones to the southeast.

Acknowledgments. We thank Nobuo Hurukawa for providing the FORTRAN code of the Modified Joint Hypocenter Determination (MJHD). We also thank Kiyoshi Yomogida and two anonymous reviewers for their careful checking our manuscript and valuable comments. The GMT system version 3.3.5 (Wessel and Smith, 1991) was used for making all figures in this paper.

\section{References}

Enescu, B., J. Mori, and S. Ohmi, Double-difference relocations of the 2004 off the Kii peninsula earthquakes, Earth Planets Space, 57, 357 362, 2005.

Hilde, T. W. C., N. Isezaki, and J. M. Wageman, Mesozoic sea-floor spreading in the north Pacific, in The Geophysics of the Pacific Ocean Basin and its Margins, Geophys. Monogr. Ser. 19, edited by G. H. Sutton, M. H. Manghnani, and R. Moberly, pp. 205-226, AGU, Washington, D. C., 1976.

Hurukawa, N., Quick aftershock relocation of the 1994 Shikotan earthquake and its fault planes, Geophys. Res. Lett., 22, 3159-3162, 1995.

Hurukawa, N. and M. Imoto, Subducting oceanic crusts of the Philippine Sea and Pacific plates and weak-zone-normal compression in the Kanto district, Japan, Geophys. J. Int., 109, 639-652, 1992.

International Seismological Centre, On-line Bulletin, http://www.isc.ac. uk/Bull, Internatl. Seis. Cent., Thatcham, United Kingdom, 2005.

Kanamori, H., Faulting of the great Kanto earthquake of 1923 as revealed by seismological data, Bull. Earthq. Res. Inst., 49, 13-18, 1971.

Kasahara, M. and T. Sasatani, Source characteristics of the Kunashiri strait earthquake of December 6, 1978 as deduced from strain seismograms, Phys. Earth Planet. Inter., 37, 124-134, 1985.

Katsumata, K., M. Ichiyanagi, M. Miwa, M. Kasahara, and H. Miyamachi, Aftershock distribution of the October 4, 1994 Mw8.3 Kurile islands earthquake determined by a local seismic network in Hokkaido, Japan, Geophys. Res. Lett., 22, 1321-1324, 1995.

Kennett, B. L. N., E. R. Engdahl, and R. Buland, Constraints on seismic velocities in the Earth from traveltimes, Geophys. J. Int., 122, 108-124, 1995.

Kikuchi, M. and H. Kanamori, The Shikotan earthquake of October 4, 1994: Lithospheric earthquake, Geophys. Res. Lett., 22, 1025-1028, 1995

Miyoshi, T. and K. Ishibashi, A tectonic interpretation of NW-SE strikeslip faulting during the 2004 off the Kii peninsula earthquake, Japan: Probable tear of the Philippine Sea plate, Earth Planets Space, 57, 1115-1120, 2005

Seno, T., T. Sakurai, and S. Stein, Can the Okhotsk plate be discriminated from the North American plate?, J. Geophys. Res., 101, 11305-11315, 1996

Takahashi, H. and K. Hirata, The 2000 Nemuro-Hanto-Oki earthquake, off eastern Hokkaido, Japan, and the high intraslab seismic activity in the southwestern Kuril Trench, J. Geophys. Res., 108(B4), 2178, doi:10. 1029/2002JB001813, 2003.

Tanioka, Y., L. Ruff, and K. Satake, The great Kurile earthquake of October 4, 1994 tore the slab, Geophys. Res. Lett., 22, 1661-1664, 1995.

Tsuji, H., Y. Hatanaka, T. Sagiya, and M. Hashimoto, Coseismic crustal deformation from the 1994 Hokkaido-Toho-Oki earthquake monitored by a nationwide continuous GPS array in Japan, Geophys. Res. Lett., 22, 1669-1672, 1995

Utsu, T., Large earthquakes near Hokkaido and the expectancy of the occurrence of a large earthquake off Nemuro, Rep. Coord. Comm. Earthq. Predict., 7, 7-13, 1972 (in Japanese).

Wessel, P. and W. H. F. Smith, Free software helps map and display data, Eos Trans. AGU, 72, 441, 445-446, 1991.

T. Harada (e-mail: haratomo@tiger.kobe-u.ac.jp) and K. Ishibashi 